\title{
Marcadores fAFLP na caracterização de três genótipos de umezeiro selecionados como porta-enxertos para pessegueiro
}

\author{
Ester Wickert ${ }^{(1)}$, Eliana Gertrudes de Macedo Lemos ${ }^{(1)}$, Fernando Mendes Pereira ${ }^{(2)}$ e Newton Alex Mayer ${ }^{(3)}$
}

\begin{abstract}
(1)Universidade Estadual Paulista (Unesp), Fac. de Ciências Agrárias e Veterinárias (FCAV), Dep. de Tecnologia, Via de Acesso Prof. Paulo Donato Castellane, s/no, CEP 14884-900 Jaboticabal, SP. E-mail: ewickert@terra.com.br, egerle@fcav.unesp.br (2)Unesp, FCAV, Dep. de Produção Vegetal. E-mail: inagrojab@yahoo.com.br ${ }^{(3)}$ Embrapa Clima Temperado, BR 392, Km 78, Caixa Postal 403, CEP $96001-970$ Pelotas, RS. E-mail: alex@cpact.embrapa.br
\end{abstract}

\begin{abstract}
Resumo - $\mathrm{O}$ objetivo deste trabalho foi caracterizar a diversidade genética existente em três genótipos de umezeiro (Clone 05, cv. Rigitano e Clone 15) e identificar marcadores moleculares fAFLP (fluorescent Amplified Fragment Lenght Polymorphism) passíveis de serem utilizados na discriminação dos três genótipos de umezeiro selecionados como porta-enxertos para pessegueiro. Foram utilizadas 24 diferentes combinações de primers seletivos fAFLP que geraram 648 marcas, das quais 272 foram diferenciadoras dos três genótipos entre si. As marcas diferenciadoras permitiram o agrupamento dos clones de umezeiro de acordo com sua similaridade através do Método da Distância e algorítmo Neighbour Joining. As mesmas marcas foram utilizadas para calcular a distância genética entre os clones. Com o uso de marcadores fAFLP foi possível discriminar os três genótipos de umezeiro entre si, destacando-se as combinações Fam ACT/CAT, Joe AGG/CTT e Ned AGC/CAA, que permitiram a diferenciação individual de cada um dos clones. A maior distância genética foi encontrada entre a cv. Rigitano e o Clone 15. Os marcadores fAFLP revelaram maior proximidade genética entre o Clone 05 e a cv. Rigitano.
\end{abstract}

Termos para indexação: Prunus mume, Prunus persica, marcador molecular.

\section{fAFLP markers to characterize three mume genotypes selected as rootstocks for peach tree}

\begin{abstract}
The objective of this work was the identification of fAFLP markers to be used in molecular characterization of three mume genotypes selected as rootstocks for peach tree. Twenty-four different fAFLP primer combinations were used and allowed the recognition of 648 markers, comprising 272 markers which were able to discriminate the three clones one from the other. These markers were used to calculate the groupment of the clones according to their similarities with the distance method and neighbour joining algorithm. The same markers were also used to calculate the genetic distance among the clones. The fAFLP markers were efficient to identify the clones, mainly by the combinations of selective primers Fam ACT/CAT, Joe AGG/CTT and Ned AGC/ CAA. fAFLP markers allowed the genetic discrimination of the three mume genotypes. The greatest genetic distance was found between Rigitano cultivar and Clone 15. The fAFLP markers also showed greater genetic similarity between Clone 05 and Rigitano cultivar.
\end{abstract}

Index terms: Prunus mume, Prunus persica, molecular markers.

\section{Introdução}

O umezeiro (Prunus mume Sieb. et Zucc.) é uma planta frutífera originária da China e pertencente à família Rosaceae. Seus frutos apresentam propriedades medicinais e são utilizados na indústria alimentícia (Kubota, 2006). No Brasil, a espécie foi introduzida no Estado de São Paulo provavelmente pelos imigrantes japoneses.

Em 1980 iniciaram-se estudos no Brasil para utilização do umezeiro como porta-enxerto para pessegueiro [Prunus persica (L.) Batsch], em razão da proximidade botânica entre as espécies. Os estudos iniciais revelaram compatibilidade da enxertia, aumento da massa dos frutos e da coloração vermelha do epicarpo, comparativamente aos frutos produzidos utilizando-se o pessegueiro 'Okinawa' como porta-enxerto (Campo Dall'orto et al., 1992). Os resultados iniciais desses autores revelaram grande variabilidade genética entre as plantas, principalmente em relação ao vigor - conseqüência da propagação do umezeiro por sementes - o que impedia a identificação precisa do porta-enxerto. 
A dificuldade na identificação correta e precisa de porta-enxertos de pessegueiro dificulta a modernização da persicultura no Brasil. O uso exclusivo de portaenxertos propagados por sementes aumenta ainda mais a variabilidade genética e torna cada indivíduo portador de características genéticas praticamente únicas. Como consequiência, observa-se a desuniformidade das plantas quanto ao vigor, diferentes reações ao ataque de pragas, doenças de solo e às condições de solo seco ou encharcado (Pereira \& Mayer, 2005). A exigência de modernização da fruticultura em razão da competitividade torna imprescindível a utilização dos avanços tecnológicos na implantação e condução de pomares e, neste processo, a utilização de porta-enxertos clonais com características de interesse e identidade genética conhecida são fundamentais.

O primeiro porta-enxerto clonal de umezeiro selecionado no Brasil com características desejáveis, especialmente resistência a Meloidogyne javanica (Mayer et al., 2003) e M. incognita (Mayer et al., 2005) e menor vigor (Mayer \& Pereira, 2006), foi a cultivar Rigitano (Pereira et al., 2007), selecionada inicialmente como Clone 10, que apresenta características morfológicas muito semelhantes a outros dois genótipos de umezeiro também selecionados pelo mesmo projeto, os Clones 05 e 15. Marcadores morfológicos mostraram performance limitada na discriminação dos três genótipos entre si, uma vez que são influenciados pelas condições ambientais e a utilização de marcadores moleculares tornou-se uma alternativa para a distinção precisa dos clones.

A identificação molecular é especialmente aplicável em espécies frutíferas, que são geralmente caracterizadas por alto nível de polimorfismo entre cultivares e pela ausência de variação dentro das cultivares devido à propagação vegetativa. A análise do DNA é ainda mais importante no caso de porta-enxertos, pois sua identificação após a enxertia é extremamente difícil (Wünsch \& Hormaza, 2002).

Marcadores AFLP (Amplified Fragment Length Polymorphisms) combinam técnicas de RFLP (Restriction Fragment Length Polymorphisms) e de PCR (Polymerase Chain Reaction), são de caráter dominante e revelam altos níveis de polimorfismo com grande número de marcadores que atuam com precisão em análises de germoplasma. Entretanto, sua aplicação em plantas frutíferas de clima temperado tem sido escassa, provavelmente em razão da maior facilidade de manuseio de outras técnicas, como os microssatélites (Wünsch \&
Hormaza, 2002). A técnica de AFLP possui vantagens em relação a outras técnicas, como a possibilidade de identificar alto nível de polimorfismo e pela sua alta reprodutibilidade (Yang et al., 2005). Outra vantagem da técnica é a possibilidade de marcação dos primers seletivos com fluorescência (fAFLP - fluorescent Amplified Fragment Lenght Polymorphism), o que permite a resolução de diferentes marcadores com diferentes fluorescências em um mesmo gel e acarreta a eliminação de uso de corantes e radioisótopos para visualização das bandas.

Marcadores AFLP foram utilizados com sucesso por Hurtado et al. (2002) para identificar fontes de resistência ao vírus sharka (PPV) em 16 cultivares de damasqueiro (Prunus armeniaca). Esses autores verificaram a formação de dois grupos principais, um formado pelas cultivares norte-americanas (todas resistentes a sharka, exceto Hargrand) e o outro formado pelas cultivares suscetíveis ao vírus. Yang et al. (2005) utilizaram esses marcadores para diferenciar 14 acessos de umezeiro produtores de flores e utilizados na ornamentação, o que possibilitou a distinção dos genótipos estudados. Os autores concluíram que o AFLP se constituía de uma técnica efetiva, barata e rápida para a diferenciação de cultivares de umezeiro.

O objetivo deste trabalho foi caracterizar a diversidade genética existente em três genótipos de umezeiro (Clone 05, cultivar Rigitano e Clone 15) e identificar marcadores moleculares fAFLP passíveis de serem utilizados na discriminação molecular dos três genótipos de umezeiro selecionados como porta-enxertos para pessegueiro.

\section{Material e Métodos}

Plantas originais dos três genótipos de umezeiro (Prunus mume Sieb. et Zucc.) foram obtidas por germinação de sementes oriundas de frutos colhidos de diferentes plantas matrizes de umezeiro cultivadas na Estação Experimental de Jundiaí, pertencente ao Instituto Agronômico (IAC). Em 1998, a partir das plantas originais mantidas em cultivo no IAC, foram colhidos ramos herbáceos de cada planta, identificados e transportados ao Ripado de Fruticultura, pertencente ao Departamento de Produção Vegetal da FCAV/Unesp, onde se iniciou o projeto com esses clones (Nachtigal et al., 1999). Dessa forma, os genitores masculino e feminino do Clone 05, da cv. Rigitano e do Clone 15 de umezeiro são desconhecidos. 
O Clone 05, a cv. Rigitano e o Clone 15 de umezeiro apresentaram características desejáveis como portaenxerto de pessegueiro e foram propagados por enraizamento de estacas herbáceas (Mayer et al., 2001). Após aclimatação em viveiro, foram transplantados para o campo em maio de $2002 \mathrm{sob}$ espaçamento de $0,5 \mathrm{~m}$ entre plantas em área experimental localizada no Sítio São João, Município de Taquaritinga, SP. Em janeiro de 2006, foram colhidas aproximadamente $300 \mathrm{~g}$ (matéria fresca) de folhas jovens de uma única planta identificada de cada clone de umezeiro. As folhas foram armazenadas em sacos de plástico identificados e colocadas em caixa de isopor contendo gelo. Do mesmo modo, também foram colhidas folhas jovens de pessegueiro [Prunus persica (L.) Batsch] da cultivarcopa Aurora-1 e do porta-enxerto 'Okinawa' e foi utilizada uma única planta de cada cultivar, ambas mantidas em condições de campo em área destinada à manutenção de plantas matrizes, também localizada no Sítio São João. As duas cultivares de pessegueiro aparentadas entre si através de progenitores comuns foram utilizadas como padrão de comparação em relação aos três clones ("outgroup").

Folhas jovens coletadas dos três clones foram lavadas, secadas com papel-toalha e maceradas com $\mathrm{N}$ líquido até a obtenção de pó fino, que foi transferido para tubos eppendorf de 2,0 mL. O DNA das amostras foi extraído conforme o protocolo de Shillito \& Saul (1988). A quantificação do DNA e sua qualidade foram realizadas com auxílio de espectrofotômetro, tendo-se medido a absorvância de cada amostra em contraste com uma amostra de $\mathrm{H}_{2} \mathrm{O}$ destilada livre de DNA nos comprimentos de onda de 260 e $280 \mathrm{~nm}$ (Sambrook et al., 1989). A qualidade do DNA foi verificada durante sua quantificação, observando-se a relação encontrada entre as leituras nos comprimentos de onda de 260 e $280 \mathrm{~nm}$, que deve ser entre 1,8 e 2,0, o que caracteriza um DNA de bom peso molecular. Para certificação da qualidade, amostras do DNA extraído foram aplicadas em gel de agarose $0,8 \%$ e submetidas a eletroforese para observação da formação de banda sem arraste.

Os marcadores fAFLP foram obtidos utilizando-se o "AFLP Regular Plant Genomes Fingerprinting Kit" (Applied Biosystems do Brasil Ltda.) de acordo com instruções do fabricante. O DNA dos isolados foi restrito com as enzimas EcoRI e MseI, ligado aos adaptadores e pré-amplificado. A amplificação seletiva foi realizada com os pares de primers de fluorescência Fam EcoRIMseI (ACT/CAC; ACA/CAC; ACT/CAA; ACA/CTC;
ACA/CTA; ACA/CAG; ACT/CAT e ACT/CTG), fluorescência Ned EcoRI-MseI (AAC/CAT; ACC/CTT; ACC/CAC; AAC/CAC; ACG/CAA/AGC/CTC; ACC/ CTG e AAC/CAG) e fluorescência Joe EcoRI-MseI (AGG/CAC;AAG/CAC; ACG/CTG; ACG/CAC; AGG/ CTT; AAG/CTA; AAG/CAA e ACG/CTC), totalizando 24 primers. As amostras foram aplicadas em um gel 5\% desnaturante Long Ranger, usando TEB 1X como tampão de corrida. Foi utilizada uma placa de seqüenciamento de $36 \mathrm{~cm}$, e 2,5 horas de tempo de corrida, a $2.500 \mathrm{~V}$ em um seqüenciador automático de DNA (ABI Prism 377), com padrão de tamanho molecular GeneScan-500 (ROX).

Foram selecionados fragmentos com tamanho entre 50 e 500 pares de bases. Na análise dos marcadores, foram utilizados os softwares GeneScan (ABI Prism versão 1.0) e Genotyper (ABI Prism versão 1.03), para a coleta dos dados e transformação em uma matriz binária. A matriz binária gerada foi analisada no software PAUP (Phylogenetic Analysis Using Parcimony versão 3.01) (Felsenstein, 1985) para a geração de matriz de distância. A matriz de distância obtida foi analisada pelo software MEGA (versão 2.1). Foram também calculados índices de distância genética intra e interespecífica entre os materiais. Esta é uma medida da diversidade genética existente entre os indivíduos de um grupo (intra-específica) e em relação a outros grupos ou indivíduos (interespecífica). A mesma matriz de distância obtida foi analisada pelo software MEGA (versão 2.1) (Kumar et al., 2004) com uso do Método de Distância, com algoritmo de agrupamento de Neighbour Joining (Saitou \& Nei, 1987) para a construção do cladograma das relações de similaridade evidenciadas pelos materiais.

\section{Resultados e Discussão}

A utilização das 24 combinações de primers permitiu a obtenção de 272 marcas moleculares diferenciadoras dos três genótipos de umezeiro $(41,9 \%)$, de um total de 648 marcas. Dessa forma, verificou-se que os marcadores moleculares fAFLP foram eficientes na caracterização da variabilidade genética existente entre os três genótipos de umezeiro, bem como entre estes e as duas cultivares de pessegueiro, que foram utilizadas como padrão de comparação para melhor visualizar as relações genéticas desenvolvidas pelos três genótipos de umezeiro. Marcas diferenciadoras entre os três clones puderam ser claramente visualizadas, utilizando- 
se diferentes combinações de primers e fluorescências (Figura 1). A combinação Fam ACT/CAT gerou quatro polimorfismos passíveis de serem utilizados na diferenciação dos três clones, de tamanhos que variaram de cerca de 95 pb a 147 pb. Já a combinação Joe AGG/ CTT gerou duas bandas diferenciadoras dos clones, com cerca de 210 e $230 \mathrm{pb}$. No caso da combinação de primers Ned AGC/CAA, duas bandas diferenciadoras próximas entre si (cerca de 170 e $180 \mathrm{pb}$ ) foram identificadas. Quando analisadas em conjunto, as bandas identificam com clareza os três clones, pois o Clone 05 tem apenas a banda de $170 \mathrm{pb}$, a cultivar Rigitano possui apenas a banda de $180 \mathrm{pb}$ e o Clone 15 possui as duas bandas (Figura 1). Desta forma, a utilização conjunta dessas três combinações de primers permite a visualização de bandas diferenciadoras e, assim, a identificação dos clones.

Marcas fAFLP também foram utilizadas com sucesso para diferenciar 17 cultivares comerciais e seis acessos tradicionais de pessegueiro japoneses (introduzidos da China), tendo-se verificado suas relações filogenéticas (Xu et al., 2006). Foi possível observar que as cultivares comerciais possuíam pouca diversidade genética e não eram relacionadas com quatro dos acessos tradicionais,

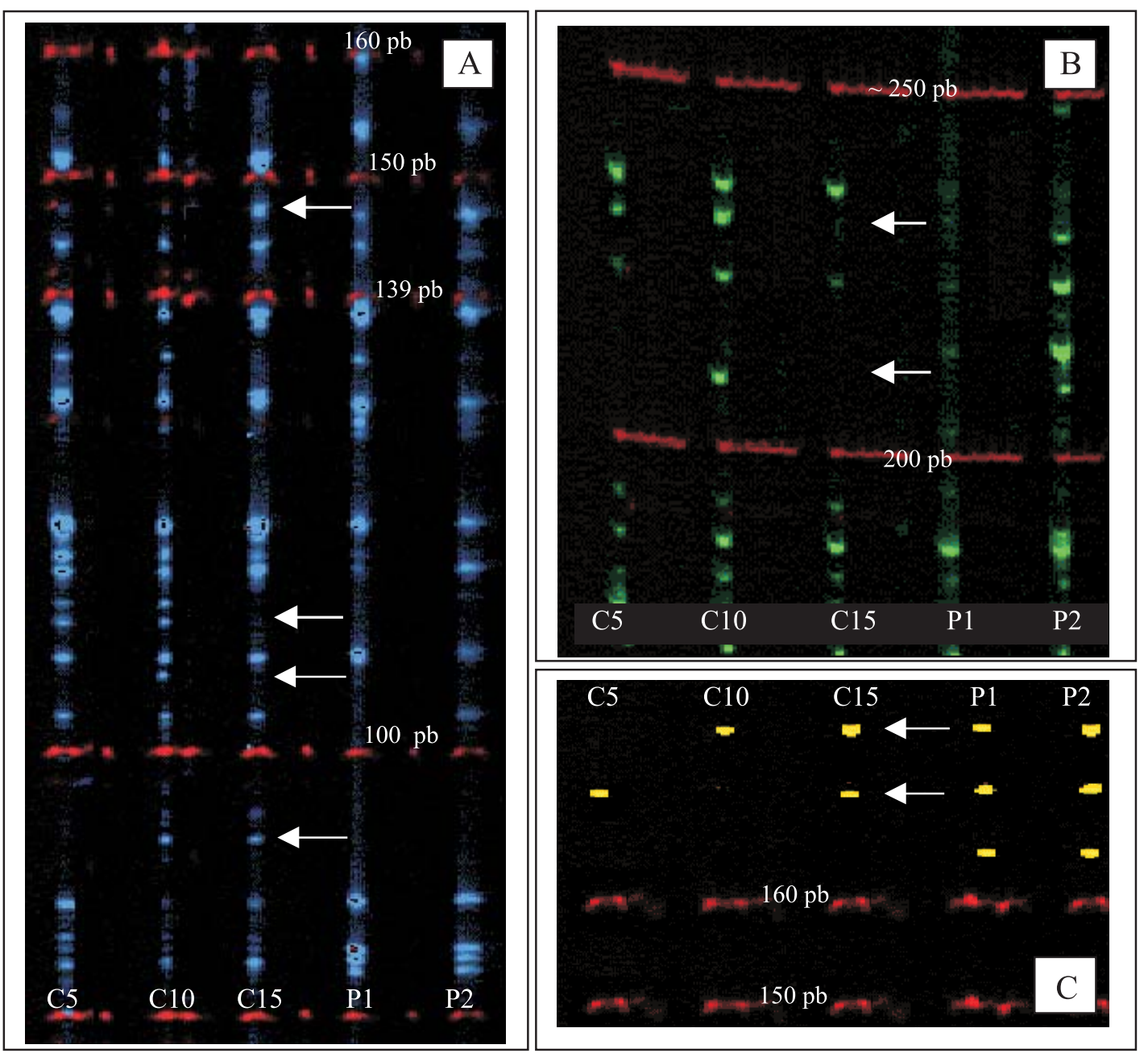

Figura 1. Padrão de amplificação dos clones de umezeiro em diferentes seções dos géis de eletroforese. A: padrão obtido em seção do gel com a utilização de Fam ACT/CAT; as quatro setas indicam variação no perfil de restrição/amplificação. B: padrão obtido com Joe AGG/CTT; as duas setas indicam variação. C: padrão obtido com Ned AGC/CAA; as duas setas indicam variação. As setas indicam algumas das bandas diferenciadoras. C5: Clone 05. C10: Clone 10 (Rigitano). C15: Clone 15. P1: pessegueiro Aurora-1. P2: pessegueiro Okinawa. Os tamanhos moleculares do padrão Rox 500 estão indicados em cada figura. 
ao passo que os outros dois acessos provavelmente possuíam relação próxima com as cultivares comerciais. Os autores advertiram para a urgência de introdução de novas cultivares de pessegueiro nos programas de melhoramento japoneses em função do estreitamento da base genética desta espécie no Japão. No caso dos três clones de umezeiro deste estudo, apesar de oriundos de plantas originais distintas, os marcadores fAFLP permitiram observar reduzida diversidade genética, embora isto possa ter sido causado pela seleção prévia dos clones utilizados para características desejáveis (Mayer et al., 2003, 2005; Mayer \& Pereira, 2006).

Os mesmos marcadores também foram utilizados para caracterização e diferenciação de oito cultivares de pessegueiro e seis cultivares de nectarineiras de importância para o comércio de exportação do Chile, com o objetivo de certificação e registro (Manubens et al., 1999). Estes autores verificaram que os marcadores foram eficientes em discriminar pessegueiros e nectarineiras entre si, bem como permitiram a caracterização de cultivares dos dois grupos.

Verificou-se também que os marcadores moleculares fAFLP diferenciaram facilmente os genótipos de umezeiro das cultivares de pessegueiro, bem como, e principalmente, entre os três clones de umezeiro estudados. Verificou-se maior similaridade entre os genótipos de cada espécie (média de 36,6 marcas para umezeiro e de 32 marcas para os pessegueiros) e grande variação entre as duas espécies (média de 83,6 marcas entre as duas espécies). Desta forma, esses marcadores podem ser utilizados na discriminação e caracterização de espécies de Prunus spp.

Com relação à diferenciação dos genótipos de umezeiro, os marcadores evidenciaram maior similaridade genética entre o Clone 05 e a cv. Rigitano, com 27 marcas diferenciais entre si e distância genética de 0,17 (Tabela 1) (similaridade genética de cerca de

Tabela 1. Distância genética e número de bandas polimórficas entre o Clone 05, cv. Rigitano e Clone 15 de umezeiro (Prunus mume Sieb. et Zucc.) e cultivares Okinawa e Aurora-1 de pessegueiro (Prunus persica (L.) Batsch) obtidas com o uso de marcadores fAFLP.

\begin{tabular}{lccccc}
\hline Genótipo & Clone 05 & Rigitano & Clone 15 & Okinawa & Aurora-1 \\
\hline Clone 05 & - & 0,17532468 & 0,26623377 & 0,49350649 & 0,55844158 \\
Rigitano & 27 & - & 0,27272728 & 0,35714287 & 0,43506494 \\
Clone 15 & 41 & 42 & - & 0,38311687 & 0,48701298 \\
Okinawa & 76 & 55 & 59 & - & 0,20779221 \\
Aurora-1 & 86 & 67 & 75 & 32 & - \\
\hline
\end{tabular}

0,83). A maior distância foi observada entre a cv. Rigitano e o Clone 15, com 42 marcas diferenciais e distância genética de 0,27 (similaridade de cerca de 0,73). Desta forma, é provável que o Clone 05 e a cultivar Rigitano tenham ancestrais comuns mais próximos do que em relação ao Clone 15. Uma vez que os parentais dos genótipos de umezeiro deste estudo não são conhecidos, pois foram obtidos de uma coleção plantada a partir de sementes das quais desconhece-se os genitores, podese inferir que talvez tenham sido originados da mesma planta-mãe mas de pais diferentes, ou ainda de mesmos parentais, porém, em sementes com diferentes taxas de recombinação.

As marcas fAFLP obtidas também permitiram o agrupamento dos genótipos de umezeiro de acordo com sua similaridade (Figura 2). O Clone 05 e a cv. Rigitano mostraram maior similaridade entre si do que em relação ao Clone 15. Desta forma verifica-se que, apesar da similaridade morfológica apresentada pelos três genótipos e das limitações em diferenciá-los visualmente, a análise por marcadores fAFLP revelou que eles são geneticamente diferentes entre si.

Hagen et al. (2002) verificaram que cultivares de damasqueiros de origem européia possuíam menor diversidade genética do que cultivares de origem asiática, o que era coerente com os conhecimentos acerca do centro de origem e disseminação da espécie. Entretanto, os mesmos autores verificaram que as cultivares americanas possuíam uma base genética diferente, ainda indeterminada, mas possivelmente originária de cruzamentos entre diferentes espécies do subgênero Prunophora e seção Armeniaca, à qual pertence P. mume.

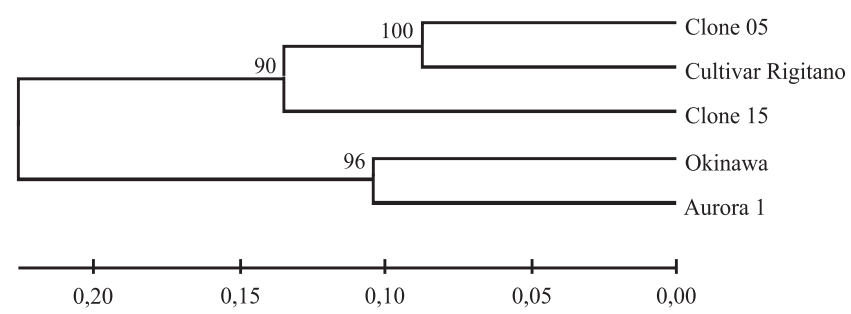

Figura 2. Relações de similaridade estabelecidas entre os clones de umezeiro através de marcadores fAFLP. Verifica-se maior similaridade entre o Clone 05 e a cv. Rigitano. Pessegueiros 'Aurora-1' e 'Okinawa' foram utilizados como "outgroup". O eixo X demonstra a distância genética dos clones. 
Nesse caso, evidencia-se que os marcadores moleculares fAFLP são uma excelente alternativa para a identificação de genótipos de umezeiro, quando da limitação ou impossibilidade de diferenciação morfológica. Como a maioria das espécies frutíferas de clima temperado é propagada vegetativamente, as marcas moleculares são importantes para a identificação de cultivares e o controle da sua propagação (Wünsch \& Hormaza, 2002).

\section{Conclusões}

1. Marcadores fAFLP permitem a discriminação dos clones de umezeiro entre si, ainda que os mesmos sejam fenotipicamente semelhantes.

2. Existe maior proximidade genética entre o Clone 05 e a cv. Rigitano do que entre estes e o Clone 15.

\section{Agradecimentos}

À Fapesp, pelo apoio financeiro.

\section{Referências}

CAMPO DALL'ORTO, F.A.; OJIMA, M.; BARBOSA, W.; MARTINS, F.P. O nanismo do pessegueiro induzido pela enxertia no damasqueiro-japonês. Pesquisa Agropecuária Brasileira, v.27, p.517-521, 1992.

FELSENSTEIN, J. Confidence limits on phylogenies: an approach using the bootstrap. Evolution, v.39, p.783-791, 1985.

HAGEN, L.S.; KHADARI, B.; LAMBERT, P.; AUDERGON, J.M. Genetic diversity in apricot revealed by AFLP markers: species and cultivar comparisons. Theoretical Applied Genetics, v.105, p.298305, 2002 .

HURTADO, M.A.; WESTMAN, A.; BECK, E.; ABBOTT, G.A.; LLÁCER, G.; BADENES, M.L. Genetic diversity in apricot cultivars based on AFLP markers. Euphytica, v.127, p.297-301, 2002.

KUBOTA, N. Stone fruits. In: Horticulture in Japan 2006. Kyoto: Shoukadoh Publication, 2006. p.60-72.

KUMAR, S.; TAMURA, K.; NEI, M. MEGA3: Integrated software for molecular evolutionary genetics analysis and sequence alignment. Briefings in Bioinformatics, v.5, p.150-163, 2004.

MANUBENS, A.; LOBOS, S.; JADUE, Y.; TORO, M.; MESSINA, R.; LLADSER, M.; SEELENFREUND, D. DNA isolation and AFLP fingerprinting of nectarine and peach varieties (Prunus persica). Plant Molecular Biology Reporter, v.17, p.255-267, 1999.

MAYER, N.A.; PEREIRA, F.M. Vigor de clones de umezeiro e pessegueiro 'Okinawa' propagados por estacas herbáceas. Pesquisa Agropecuária Brasileira, v.41, p.883-887, 2006.

MAYER, N.A.; PEREIRA, F.M.; NACHTIGAL, J.C. Propagação do umezeiro (Prunus mume Sieb \& Zucc.) por estaquia herbácea. Revista Brasileira de Fruticultura, v.23, p.673-676, 2001.

MAYER, N.A.; PEREIRA, F.M.; SANTOS, J.M. Reação de clones de umezeiro (Prunus mume Sieb. et Zucc.) e cultivares de pessegueiro a Meloidogyne javanica (Treub, 1885) Chitwood, 1949. Revista Brasileira de Fruticultura, v.25, p.181-183, 2003.

MAYER, N.A.; PEREIRA, F.M.; SANTOS, J.M. dos. Resistência de clones de umezeiro e cultivares de pessegueiro a Meloidogyne incognita (Nemata: Heteroderidae). Revista Brasileira de Fruticultura, v.27, p.335-337, 2005.

NACHTIGAL, J.C.; PEREIRA, F.M.; CAMPO DALL'ORTO, F.A.; OJIMA, M.; MARTINS, F.P. Propagação vegetativa do umezeiro (Prunus mume) por meio de estacas herbáceas. Revista Brasileira de Fruticultura, v.21, p.226-228, 1999.

PEREIRA, F.M.; MAYER, N.A. Pessegueiro: tecnologias para a produção de mudas. Jaboticabal: Funep, 2005. 65p.

PEREIRA, F.M.; MAYER, N.A.; CAMPO DALL'ORTO, F.A. 'Rigitano': nova cultivar de umezeiro para porta-enxerto de pessegueiro. Revista Brasileira de Fruticultura, v.29, p.172-175, 2007.

SAITOU, N.; NEI, M. The neighbor-joining method: a new method for reconstructing phylogenetic trees. Molecular Biology and Evolution, v.4, p.406-425, 1987.

SAMBROOK, J.; MANIATIS, T.; FRITSH, E.F. Molecular cloning: a laboratory manual. 2.ed. New York: Cold Spring Harbor Laboratory, 1989.

SHILliTO, R.D.; SAUL, M.W. Protoplast isolation and transformation. In: SHAW, C.H. (Ed.). Plant molecular biology: a practical approach. Oxford: IRL Press, 1988. p.161-186,

WÜNSCH, A.; HORMAZA, J.I. Cultivar identification and genetic fingerprinting of temperate fruit tree species using DNA markers. Euphytica, v.125, p.59-67, 2002.

XU, D.H.; WAHYUNI, S.; SATO, Y.; YAMAGUCHI, M.; TSUNEMATSU, H.; BAN, T. Genetic diversity and relationships os japanese peach (Prunus persica L.) cultivars revealed by AFLP and pedigree tracing. Genetic Resources and Crop Evolution, v.53, p.883-889, 2006.

YANG, C.; ZHANG, J.; XU, Q.; XIONG, C.; BAO, M. Establishment of AFLP technique and assessment of primer combinations for mei flower. Plant Molecular Biology Reporter, v.23, p.79a.-791, 2005.

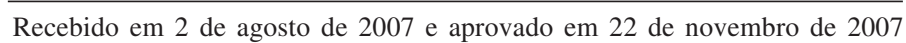

